\title{
Commentary
}

\section{From free chromatin analysis to high resolution fiber FISH $^{1}$}

\author{
HENG Henry HQ**,*,2 Xiao Mei SHI*** \\ * Department of Biology, York University, Downsview, \\ oN, Canada \\ ** SeeDNA Biotech Inc., Downsview, ON, Canada \\ *** Department of Genetics, The Hospital of Sick \\ Children, Toronto ON, Canada
}

\begin{abstract}
Key words: Free chromatin, fiber-FISH, physical mapping, chromosome and genome.
\end{abstract}

Fluorescent in situ hybridization (FISH) methodology is one of the most powerful and versatile experimental systems for current biology. It bridges the molecular biology and cytology by providing direct and precise research tools for gene mapping, chromosomal structure study and genome analysis[1]. One major breakthrough for FISH analysis, is the introduction of the concept and methodologies of high resolution fiber FISH[2, 3]. By FISH detecting on released, less condensed, and linearized chromatin or DNA fibers, the ultra high resolution mapping data can be generated over the conventional chr0mosome-based FISH or interphase FISH[4], making a significant contribution for current genome project. This novel approach also provides an ideal tool for chromosome and genome structure and function studies[5-8].

\section{Hypothesis of high resolution FISH mapping using released chro- matin}

The resolution of FISH detection depends on the target of hybridization. From DNA to metaphase chromosomes, DNA molecules are packaged to approximately

1. Dedicated to the 80 th birthday of Professor Lu Ji SHI

2. Corresponding author.

Mailing address: Dr. Henry H.Q. Heng, Biology Department, York University, 4700 Keele ST, Downsview, Ontario, Canada M3J1P3, (416) 617-8758 (tel), (416) 736-5731 (fax), fs300025 sol, yorku.ca (email) 
From free chromatin analysis to high resolution fiber FISH

10,000 times. Thus, it is difficult to obtain high resolution data from condensed chromosomes. Less condensed chromatin of interphase nuclei or surface-spread pachytene chromosomes were used to solve this problem in certain degree[9-10].

The use of released chromatin fibers for FISH mapping based on our hypothesis that the chromatin can be released from nuclei and, while the three dimensional organization of the chromatin is reduced into two dimensional linear fiber, the physical mapping information is preserved. The released chromatin fiber can also be used as the hybridization targets for FISH detection, so the physical mapping information can be "read out" directly from the chromatin fiber. If succeeded, this approach should also be very useful for studying chromosome and genome structure in addition to physical mapping, for it opens a window to directly visualize DNA fragments and DNA/protein complexes at various level of chromatin condensation, allowing one to trace the process of high order structure formation. In fact, this powerful experimental system was initially developed in China when one of us $(\mathrm{HHQH})$ was a graduate student over 15 years ago.

\section{Free chromatin: Chromatin or not ? Useful or not?}

In 1982 , to establish the method to band the amphibian chromosome, the protocol of using less condensed prophase chromosomes were introduced by us under the supervision of Prof. Wen Yuan Chen from Sichuan University. By control the degree of chromosomal condensation, this research not only generated the effective banding methods for studying amphibian chromosome[11-12], but also led to an exciting discovery that various forms of chromatin can be found after conventional chromosomal slide preparation[13-15]. Feulgen staining, ${ }^{3} \mathrm{H}$-labelling and DAPI staining have demonstrated that these "rope" and "spindle"-like materials were DNA-containing fibers rather than the non-chromatin structures generated during slide preparation. NOR (Nuclear Organizer region) staining and electron microscopy analysis further showed that these structures were chromatins and there is no visible nuclear envelope surrounding these $30 \mathrm{~nm}$ chromatin fibers. "Free chromatin" was then used to describe these released chromatin. Our research also demonstrated that free chromatin can be generated from different animal and plant cells and certain reagents can increase their frequency[16-17] Interestingly, our results suggested that in addition to the use of studying the high order structure formation of chromosome free chromatin should also be used for the high resolution gene mapping[18]. Unfortunately, however, due to their unconventional morphology, the free chromatin and other structure we observed were suspected to be non-chromatin artifacts. In fact, so many investigators have noticed such structures from the very beginning of their career being a cytogenetist. They firmly thought that these structures are non-chromatin contaminations. A few scientists agreed that these might be chromatin after reviewing our data, nevertheless, they doubted the usefulness of released free chromatin. As to any new discoveries, we certainly raised mon. questions than 
we could answer. Another factor was, our concepts and hypothesis contradicted to a decades-long conventional assumption regarding the nature of free chromatin, therefore we had great difficulty even in reporting our findings to national and international journals. With the encouragement and help from Drs. Lu Ji SHI, Zu Dong LIU, Yong Chao WANG, Ji Liang FU, Li Min SHI, Ming WU, D. H. Hamer, A. K. Sharma, T. H. Yoshida and C. L. Markert, we continued to push to introduce our ideas and experimental systems to others and try to convince more investigators in this field to use free chromatin, sister unit fiber and uncompleted-packing-mitoticfigures. Despite of our efforts, this research has finally been interrupted for another 5 years since the appearance of our initial reports for the reason that cytogenetics community showed almost no interests to this new development.

One crucial step to enhance the free chromatin research is to demonstrate its unique power for chromosomal research. In 1987, these various chromatin fibers were recognized as candidates for in situ hybridization mapping[18]. However, questions were raised about the legitimacy of these fibers and its application for gene mapping. It was not until at the demand of the Human Genome Project that free chromatin fiber was resurrected.

After years of frustration, one of us (HHQH) fortunately met Dr. Lap Chee Tsui at University of Toronto. He immediately realized the value of using free chromatin in generating high resolution physical map and encouraged Henry Heng to stay in his Lab for a trial experiment. To identify the specific target of chromosomes or geneome, we decided to combine free chromatin with fluorescent in situ hybridization (FISH) to answer many related questions, such as, how to generate free chromatin? can FISH be effectively performed on extended chromatin structure? Whether or not the gene order can be preserved on the released chromatin fiber?

After one more years' hard working, in 1991, we finally submitted our primary results to the 8th international conference of human Genetics at Washington, USA[2]. Our work initiated a new experimental system of high resolution FISH by demonstrating the feasibility of FISH detection along released free chromatin fiber and opening up the possibility of using even more decondensed DNA fibers to order genes or DNA fragments.

During the course of free chromatin FISH development, valuable supports have come from many scientists, including Drs. Peter Moens and Barbara Spyropoulos from York University in Canada, and David Ward from Yale University in USA.

\section{Fiber FISH}

Further modifications immediately followed to simplify the procedure for the fiber generation and to improve the resolution. To establish a protocol suitable for all type of cultured cells, alkaline releasing buffer was introduced to open the nuclear envelope since nuclear membrane is unstable under high-pH condition[3]. Alternative approaches were established by generating chromatin fiber with alkaline 
From free chromatin analysis to high resolution fiber FISH

treatment or DNA fiber with DNA "halo" preparations[19]. Within two years, more straight forward releasing methods were introduced by different groups based on the use of alkaline solution, non-ionic detergents, SDS and with or without mechanical force to stretch chromatin or DNA on glass slides[20-25].

Since all these protocols, including "molecular combing" [26-27], are to generate linearlized chromatin or DNA fiber, the key difference between them is the method of release and the degree of condensation. FISH detection is essentially the same as chromosome-based FISH. Various names have been used to describe released chromatin or DNA fibers generated by different protocols including free chromatin, free DNA, extended chromatin fiber, extended DNA fiber, elongated chromatin or DNA fiber, DNA halo, single molecule, and individual stretched DNA molecules. Recently, it has been suggested that all high resolution chromatin and DNA fiber FISH methods should be simply referred to as fiber-FISH[28].

Increasing evidences have showed that the fiber FISH methodology plays an important role for physical mapping and gene identification, especially for constructing a fine integrated genetic and physical map for sequencing[5, 29-31]. With the development of the human genome projects, fiber FISH should have more applications for studying the function aspects of the genome. Combined with our recent developed methodology of DNA-protein in situ co-detection[32-34], for instance, fiber FISH will contribute greatly to study the chromosomal/genome structure and function including DNA replication, gene integration, gene amplification, and gene regulation[1, 8].

Every time, when other scientists make new discoveries by using fiber FISH approach, it always reminds us of the early days of free chromatin research. The beauty of being a scientist is to discover, to convince others and to make full use of his/her discovery for more people, no matter how trivial it is. Free chromatin is just such an example.

\section{ACKNOWLEDGEMENTS}

This work was partially supported by SeeDNA Biotech Inc. We thank Drs. Lap Chee Tsui, Peter B Moens and Barbara for their guidance and support. Thanks also belong to Drs, L-J Shi, W-Y Chen, Y-C Wang, J-L Fu, F-T Kao, D.H. Hamer, D. Ward, B Spyropoulos and C.L. Markert for their advice, encouragement and help.

\section{REFERENCES}

[1] Heng HHQ, Spyropoulos B, Moens P. Fish technology in chromosome and genome research. Bio Essays 1977; 10:75-84.

[2] Heng HHQ, Squire J, Tsui LC. Chromatin mapping - a strategy for physical characterization of the human genome by hybridization in situ. Proc 8th Int Cong Hum Gen Am J Hum Genet $1991 ; 49: 368$.

[3] Heng HHQ, Squire J, Tsui LC. High resolution mapping of mammalian genes by in situ hybridization to free chromatin. Proc Natl Acad Sci USA 1992: 89:9509-13. 


\section{Heng HHQ and XM Shi}

[4] Heng HHQ, Tsui LC. Modes of DAPI banding and simultaneous in situ hybridization. Chromosoma 1993; 102:325-32.

[5] Heiskanen M, Peltonen L, Palotie A. Visual mapping by high resolution FISH. TIG 1996; 12:37982.

[6] Heiskanen M, Kallioniemi O, Palotie A. Fiber-FISH: experiences and a refined protocol. Genetic Analysis: Biomolecular Engineering 1996; 12:179-84.

[7] Raap AK, Florijn, R J, Blonden, LAJ et al. Fiber FISH as a DNA mapping tool, Methods: a companion to methods in enzymology. 1996; 9:67-73.

[8] Heng HHQ, Tsui LC. High resolution free chromatin and DNA fiber FISH. Book chapter in Genome Analysis. CRC Press 1997: (in press).

[9] Lawrence JB, Villnave CA, Singer RH. Sensitive, high resolution chromatin and chromosome mapping in situ: presence and orientation of two closely integrated copies of EBV in a lymphoma line. Cell 1988; 52:51-61.

[10] Moens PB, Pearlman RE. In situ DNA sequence mapping with surface-spread mouse pachytene chromosomes. Cytogenet Cell Genet 1990; 53:219-20.

[11] Heng HHQ, Zhao XL, Bei X. The high resolution banding for the frog chromosomes. Zoological research (in Chinese) 1985; 5:29-31.

[12] Heng HHQ, Chen WY, Yosida TH. Studies on amphibian chromosomes by the high resolution banding technique used for the high resolution R-banding in frogs. Proc Jap Acad 1986; 62:53-6.

[13] Heng HHQ, Chen WY. The study of the chromatin and the chromosome structure for Bufo gargarizans by light microscope. J Sichuan Univ Nat Sci 1985; 22:105-9.

[14] Heng HHQ, Chen WY. Studies on the structure of the chromosome and its formation, I. A new method. The Nucleus 1986; 29:5-8.

[15] Heng HHQ, Lin R, Zhao XL, Chen WY. Structure of the chromosome and its formation, II. Studies of the sister unit fibers. The Nucleus 1987; 30:2-9.

[16] Heng HHQ, Chen WY, Wang YC. Effects of pingyanymycin on chromosomes: A possible structural basis for chromosome aberration. Mutation Res 1987; 199:199-205.

[17] Heng HHQ, Chen WY. Studies of the late G2 chromatin structure and the chromosome formation. Acta Genet Sinica 1987; 14:237-42.

[18] Heng HHQ, Zhao XL. Studies of the free chromatin structure. J Sichuan Univ Nat Sci Edi 1987; 24:479-85.

[19] Wiegant J, Kalle W, Mullenders Let al. High resolution in situ hybridization using DNA halo preparation. Hum Mol Genet 1992; 1:587-92.

[20] Parra I, Windle B. High resolution visual mapping of stretched DNA by fluorescent hybridization. Nature Genet 1993; 5:17-21.

[21] Houseal TW, Dackowski WR, Landes GM, Klinger KW. High resolution mapping of overlapping cosmids by fluorescence in situ hybridization. Cytometry 1994; 15:193-8.

[22] Fidlerova H, Senger G, Kost M, Sanseau P, Sheer, D. Two simple procedures for releasing chromatin from routinely fixed cells for fluorescence in situ hybridization. Cytogenet. Cell Genet 1994; 65:203-5.

[23] Zhu HM, Lee ML, Sciorra JL. Use of nonionic detergent (NP-40) on standard chromosome preparations to generate free chromatin for fluorescence in situ hybridization studies. Am J Hum Genet 1993; 53:(Suppl) 1377A.

[24] Haaf T, Ward DC. High resolution ordering of YAC contigs using extended chromatin and chromosomes. Hum Mol Genet 1994: 3:629-33.

[25] Heiskanen M, Karhu R, Hellsten E, Peltonen L, Kallioniemi OP, Palotie A. High resolutionmapping using fluorescence in situ hybridization to extended DNA fibers prepared from agarose embedded cells. Bio Techniques. 1994; 17:928-33.

[26] Bensimon A, Simon A, Chiffaudel A, Croquette V, Heslot F, Bensimon D. Alignment and sensitive detection of DNA by a moving interface. Science 1994; 265:2096-8. 


\section{From free chromatin analysis to high resolution fiber FISH}

[27] Weber HUG, Wang M, Mullikin JC et al. Quantitative DNA fiber mapping. Hum Mol Genet 1995: 4:1903-9.

[28] Florijn R J, Bonden A J, Vrolijk H et al. High-resolution DNA fiber-FISH for genomic DNA mapping and color bar-coding of large genes. Hum Mole Genet 1995; 4:831-6.

[29] Heng HHQ, Tsui LC, Windle B, Parra I. High resolution FISH analysis. In: Dracopoli et al eds. Curr Prot Hum Genet John Wiley and Sons: New York 1995: 4.5.1-4.5.25.

[30] Heng HHQ, Tsui LC. Free chromatin mapping by FISH. In: Choo KHA eds Methods in Molecular Biology: Vol 33: In situ hybridization protocols. Humana Press: Totowa 1994; 109-22.

[31] van Ommen GB, Breuning HM, Raap KA. FISH in genome research and molecular diagnostics. Current opinion in genetics and development 1995; 5:304-8.

[32] Heng HHQ, Tsui LC, Moens PB. Organization of heterologous DNA inserts on the mouse meiotic chromosome core. Chromosoma 1994: 103:401-7.

[33] Heng HHQ, Chamberlain JW, Shi XM, Spyropoulos B, Tsui LC, Moens PB. Regulation of meiotic chromatin loop size by chromosomal position. Proc Natl Acad Sci USA 1996; 93:2795800.

[34] Heng HHQ, Spyropoulos B, Moens PB. Mammalian meiotic chromosome analysis by genome manipulation and DNA-protein co-detection. Analytical Biotechnology: Genome Analysis 1997: (in press). 